\title{
Proceeding
}

Supplementary Issue: Summer Conferences of Sports Science. First International Conference in Iraq on Sport for Peace, 4 April

2019. Baghdad Science Institute, Baghdad, Iraq.

\section{Management efficiency and its impact on managing the aviation insurance portfolio: An empirical study at the National Insurance Company in Iraq}

\author{
HALLA NASSER KATIE $\triangle$, ALAA ABDUL KARIM HADI AL-BALDAWI \\ Institute for Accounting and Financial Studies, Department of Financial Studies, University of Baghdad, Iraq
}

\begin{abstract}
This study aimed to look for the possibility of a possible relationship between the ratios of administrative efficiency, and the management of the aviation insurance portfolio in terms of return ratios and profitability of the portfolio of the national insurance company during the period (2011-2016). The study will try to achieve these objectives based on the methods of statistical and financial analysis, where the statistical program SPSS was used to analyse the data, in addition to the average rate of change or growth during the period of investigation and the relationship between both the ratios studied the administrative efficiency and Reinsurance ratios to see the impact of each of these ratios on the profitability of the portfolio, using a simple regression. The present research concludes that managing the insurance company's functions, particularly reinsurance efficiently, affects and reflects clearly and significantly on the profitability and success of this company and that the insurance on aircraft is considered a high-premium insurance product that generates good profits for insurance companies. However, the study showed a weakness of link in the administrative efficiency of the National Insurance Company, as its retention rate of substandard aviation insurance premium is scored around $50 \%$ of the total subscription. This indicates the company's total reliance on reinsurance and the insurance company's exposure to the risk of reinsurance. The study recommended working to improve the management efficiency of insurance companies by holding training courses that will improve employee productivity and reduce expenses by better managing the company's assets. The national insurance company should benefit from the experience of the reinsurer in training its technical staff in surveying and managing risks, which leads to reduced losses. Keywords: Administrative efficiency; Aviation insurance; Reinsurance; Profitability.
\end{abstract}

\section{Cite this article as:}

Katie, H.N., \& Al-Baldawi, A.A.K.H. (2019). Management efficiency and its impact on managing the aviation insurance portfolio: An empirical study at the National Insurance Company in Iraq. Journal of Human Sport and Exercise, 14(5proc), S2091-S2102. doi:https://doi.org/10.14198/jhse.2019.14.Proc5.30

Corresponding author. Institute for Accounting and Financial Studies, Department of Financial Studies, University of Baghdad, Iraq.

E-mail: G.S.Dabuzova4@gmail.com

Supplementary Issue: Summer Conferences of Sports Science. First International Conference in Iraq on Sport for Peace, 4 April 2019. Baghdad Science Institute, Baghdad, Iraq.

JOURNAL OF HUMAN SPORT \& EXERCISE ISSN 1988-5202

(c) Faculty of Education. University of Alicante

doi:10.14198/jhse.2019.14.Proc5.30 


\section{INTRODUCTION}

The individual is exposed in his life to a lot of dangers, and encounters harsh conditions that he cannot face with his own means, so he is moving towards the search for means and methods that narrow for him the limits of losses resulting from these risks and then the idea of insurance has emerged. The insurance is important given the role what it does in contemporary life, so that we find it pervasive in most activities, insurance due to the trading and employment of capital leads to very important economic results. Including that insurance capital feeds the financial, domestic and international market, furthermore insurance is one of the most important means of saving and investing, as well as that Insurance is a social interest. Aviation insurance is the latest insurance, which is emerging, and a highly specialized field designed to meet the general aviation needs. Some insurance companies offer aviation insurance using their own contracts. Others participate in one of the multiple aviation complexes or insurance groups specializing in offering aircraft insurance exclusively. Since the exposure to damage is significant, relative to the number of aircraft insured, and because of the highly specialized subscription, most insurance companies prefer to participate in one of the multiple aviation complexes or subscription groups specializing in writing aircraft coverage (Safdari \& Asadi, 2013). There are now enough insurance companies to deal with most aviation risks. In view of highly specialized problems and potentially catastrophic losses, it is necessary to provide sufficient market capacity to secure aviation. Often, insurance companies and reinsurers around the world are required to provide sufficient limits for aviation insurance.

\section{RESEARCH METHODOLOGY}

\section{Research Problem}

The focus of the problem for present research us how to manage the airline insurance portfolio of the national insurance company, which receives only small percentages of the total premiums subscribed to overall aviation insurance portfolio. While the large percentages go to global insurance companies monopolizing and controlling this sector and this has a direct impact on the profitability of the portfolio, which is reflected in the insurance prices and the company's competitive position, can be summarized in the following question:

- What is the impact of administrative efficiency on the management of the aviation insurance portfolio in terms of profitability?

\section{Research Objectives}

There are various main objectives of the present research, below are some of the highlighted objectives of the study.

- To clarify the economic importance of aviation insurance.

- Study the impact of the administrative efficiency of determining the size of retention on the management of the aviation insurance portfolio, reinsurance, profitability successfully during the research period.

- Reveal the reasons for the low retention rates and increase disinsurance premiums at the National Insurance Company.

\section{Importance of the Research}

There is no doubt that the success of any company in its business depends first on the management of this company efficiently and effectively leading it to success. In the business such as Insurance to manage these functions efficiently enables them to make the most of the performance of each job, especially the reinsurance function of the aviation portfolio. Given the importance of the aviation sector in promoting and supporting the local economy, it is considered an insurance product that makes good profits for insurance companies by 
taking into account the use of appropriate reinsurance agreements. This research can be a starting point for another research in this field.

\section{Research Hypothesis}

Based on the aforementioned discussion and significance of the present study, below are the hypothesis for the present study.

- There is no statistically significant relationship between administrative efficiency and the reinsurance of the aviation insurance portfolio.

- There is no statistically significant relationship between the administrative efficiency and profitability of the aviation insurance portfolio.

\section{Study Community}

The research community for the present study is the Iraqi insurance market and the national insurance company has been chosen as the parent and leading company, one of the largest Iraqi companies operating in the insurance sector and alone with the aviation branch insurance company.

\section{Research Timeframe}

The research focuses on the inductive approach based on the literature-related writings of the study and the descriptive analytical approach based on the data of the National Insurance Company, and for the period from 2011-2016.

\section{Variables of the Study}

Independent Variable

\section{The Ratio of Administrative Efficiency Ratio}

The ratio of administrative efficiency is measured by dividing the net premiums by the total premiums and the acceptable rate for this percentage is more than $50 \%$, as this percentage indicates the extent of reinsurance dependence. The ratio indicated how efficiently the management of insurance companies is in the use of their assets and generating profitable returns from the investment (Guy Callendar, 2009).

Rate of retention of insurance insinuation $=\frac{\text { Net Written Premiums }}{E \text { quity Writtem Premiums }}$

\section{Profitability}

Profitability has been measured at the rate of excess insurance activity, subscription and investment profits. The underwriting capacity of the insurance company begins by estimating the company's financial capacity to subscribe. If the insurance company has an insufficient level of profits, the surplus or compensation reserve will also be insufficient. This may hinder the company's ability to accept new risks, and the higher the surplus or compensation reserve, the more this shows the company's ability to meet its obligations according to their due dates. This percentage should not be less than $150 \%$, and its decrease indicates the inability of the company to cover the funds at risk. Therefore, there is a defect in the company's underwriting policy and calculate this percentage as follows:

The rate of surplus insurance activity = excess insurance activity $/$ net premiums subscribed $\%$ 


\section{THEORETICAL FRAMEWORK FOR RESEARCH}

First: Administrative efficiency - The Concept of Efficiency and Administrative Efficiency

Efficiency in a simple sense means being able to do things right and although this proposition is simple, it offers a linguistic concept and a clear and clear meaning. Efficiency is "knowing the proper behaviour in complex and difficult professional circumstances that we can call threats and exploiting all the opportunities it has to achieve the objectives of the institution". Efficiency is defined as the ability to perform the required duties in the best way and with the lowest possible costs in terms of time and effort, and we will undoubtedly note the association of this concept with management and its ability to guide the business to ensure its success (Amoura, 2011)

\section{The Importance of Administrative Competencies in Organizations}

In the current era, competencies are an important element in the organization's competitiveness, as the organization has a system of competencies that has a continuous ability to give in line with the requirements of the competitive arena. Since the efficiency is what makes excellence in exploiting the organization's resources in the best way improves performance indicators, such as productivity, profitability, cost reduction, price reduction and quality increases, and in order to optimize the utilization of its resources. It requires the existence of high human competencies as the only resource capable of creating value (i.e. generating products equivalent to the client's value is greater because of its quality and performance. Which improves the handling of different situations and the performance of tasks effectively, which improves the image of the organization (Mahmoud, 2005; Abbasi \& Zare, 2016).

\section{Efficiency Characteristics}

Efficiency characteristics and features in the following elements. Firstly, efficiency is a process because it involves a set of tools and tools to address problems. Secondly, Efficiency is a system of efficiency is a system of integration of knowledge in a broad sense i.e. knowledge, skills, behaviours and so on. Thirdly, the multiplicity of its resources efficiency requires a range of resources, building efficiency does not depend only on knowledge or skills, but efficiency helps to act or solve professional problems in a satisfactory manner in special circumstances by recruiting different capacities and by integrating them(Lutai et al, 2011). Fourthly, its association with the activity is not efficient unless used in an activity. Lastly, consistency and coherence efficiency need to be recruited into an activity by a certain number of personal resources (knowledge, skills, behaviours) and linked in a special way and these resources are supported by the recruitment of ocean resources."

\section{Administrative Efficiency in Insurance Companies}

Insurance companies are like any profit-seeking business, sustained and growing business organization to reflect success in a highly competitive market. Given the different functions performed by insurance companies from other companies, the efficiency factor in the management of insurance companies is highlighted in a way that can be considered private, through the management of the insurance company seeking (Al-Ghusin \& Nabil Zaher ,2014). Setting the price of insurance policies that are economically optimal for the company and the most attractive to the insurance applicant through the pricing function. The development of the optimal policy in accepting insurance so that the numbers of insurance policies accepted correspond to the company's capacity on the one hand and achieve satisfactory percentages of profits on the other hand through the underwriting function. Payment of dues and compensation to the insured after ascertaining the causes and consequences of the occurrence of the insured risk in the best way and shorter time through the claim settlement function. Issuing the right amount and size of insurance policies that are compatible with the company's method and objectives and seek to market them in the best way through the 
production function. Increase the company's ability to accept large-scale risk insurance. While maintaining a convenience and stability of profits through the reinsurance function to make the most of the insurance premiums, collected by employing them in the most returning investment areas taking into account the amounts to be kept with the company to compensate for the potential risks that occur through the investment function. Achieving the above is an expression of the efficiency of management in the insurance company, where it is one of the factors affecting the success of the company. Profitability, continuity and growth and as a result the management of the insurance company's functions efficiently affects and reflects clearly and significantly on the success and profitability of this company. Based on the above discussion, the ratio of administrative efficiency has been measured by dividing the net premiums by the total premiums and the acceptable rate for this percentage is more than $50 \%$. However, if this percentage indicates the extent of reinsurance reinsurance, the more this percentage indicates the efficiency of the management of insurance companies in the use of their assets and take over $\mathrm{D}$. The rewarding returns of them (Coetzee \& Mammen, 2017).

\section{The Aviation Insurance}

Aviation insurance is one of the most important types of insurance, as it is distinguished from other branches of insurance such as cars, fire, engineering, property and responsibilities. The geographical limits of the aviation contract cover all parts of the world, because the countries that pass through the aircraft are subject to any accident or claim, and the aviation insurance contract is a mandatory major contract. And comprehensive (Insurance and knowledge,2012).

\section{The history of the origin and development of aviation insurance}

No one knows exactly when man's first attempts to fly began, but it is known that Orville Wright was the first man to successfully fly with an engine machine in 1903 and was followed by his brother Wilber Wright (Hussein, 2011), individually and for the first time in the early 20th century (Dewi \& Ahamat, 2019). While there is a debate about the time of writing the first insurance policy, aviation insurance is a type of insurance, compared to both marine insurance and land insurance. Due to the risks of air transport, its seriousness and serious repercussions, so we find most countries resorted to introducing a mandatory system Air insurance. In this area we find that some countries make air insurance a condition for the delivery of air transport documents, including what makes it a guarantee for the operation of air transport institutions (Radhia, 2017). Aviation insurance began in 1911 when the first policy was developed by Lloyd of London, in July 1912, Lloyd's agreed to cover legal liability for third-party damages, and there was a slow development in aviation insurance from that date until the end of world war. After 1925, there was an expansion of aviation insurance to cover the risks of liability, fire and accident hazards. Since 1928, insurance companies have formed groups in the United States of America, it is clear that the commercial aviation industry and the aviation insurance industry are linked, meaning that the former would not have come into existence without the latter. Similarly, the development of commercial air services is also linked to world wars. World War I and World War II have had an effective impact on the growth of the aircraft industry, aviation uses for transportation have evolved after World War II and the number of companies practicing aviation insurance has increased in all global markets (Pena, 2006). Due to the international air characteristics it has Several international agreements and treaties have been concluded to establish rules specifying the compensation sought by the owner of the aircraft when responsible for damage to passengers, baggage or cargo on board. In 1929, the Warsaw Treaty was convened to standardize the rules on international air transport, to regulate the liability limits of aircraft operators and the amount of compensation paid in cases of accidents that cause bodily or material damage to luggage and goods transported internationally by air. In 1933, the Rome Convention was convened to standardize the rules on damage caused by aircraft to a third party on the ground, and in 1955 the Hague Protocol included international amendments. The Warsaw Convention of 1929 by raising the amount of 
compensation for physical injuries to be in line with an event of price increases during the World War II and its aftermath (Hussein, 2014), the Montreal Convention of 1966 included amendments to the Treaty of The Hague by raising the amounts of compensation for bodily injuries or death of any passenger.

\section{Definition of Aviation Insurance and its Types}

There is no formal definition of aviation insurance specifically, but Margo has given him the following broad concept: aviation insurance includes insurance for the risks associated with such as:

- Manufacture, ownership, operation and maintenance of aircraft, and

- The operation of rooftop flight facilities (Margo, 2000).

A - Aviation Insurance Items

There are types of covers against flight hazards, including the following as suggested by (Al-Halbawi, 2009)

- Insurance on the fuselage includes the fuselage, engines, furniture and all other accessories.

- Insure of civil liability to passengers and others, under which passengers or other persons and their families are paid for damages caused by aviation hazards.

- Insurance against damage to cargo on board aircraft.

\section{B- Underwriting and Pricing Considerations}

Since aviation insurance is not subject in pricing to any type of known tariffs, it is priced and the terms of the majority of its insurance in the London market are determined as the global market. Specialized in the insurance and reinsurance of this branch, and it is customary in the insurance of aviation not to use standard printed insurance orders. It was agreed that the risk data for which the insurance required could be included briefly in the form of a statement submitted by the insurance applicant (airline) to the insurer (Hassan, 2004).

C - The Most Important of Collected Data (Insurance Schools: 2014);

- Data on the aircraft or aircraft to be insured.

- Data on the structure of the aircraft by manufacturer, type and year of manufacture the number of seats - registration and is determined in accordance with international conventions.

- Data on engines of their type such as number and manufacturer.

- Data on the total value of the aircraft or aircraft, the value of the aircraft, the date of purchase, the current value of the aircraft, the value and data of other equipment.

- Data on the purpose in which the aircraft is used - the geographical scope and the person carrying out maintenance operations.

- Data for pilots such as name and age, as well as the type of aircraft they have previously piloted, the number of flying hours in each model, and the driver's license (date, type and number).

$D$ - Factors influencing the determination of the premium of insurance

The premium or instalment value of the aircraft body insurance policy depends on a combination of factors (Edman, 2019):

- The Size of the Aircraft - Aircraft insurance rates are inversely proportional to aircraft sizes.

- Type of Aircraft - The rates of insurance for seaplanes are higher than those for ground aircraft to increase the risk of docking at ports than landing at airports.

- The Age of the Plane - The average price of insurance for an aircraft of the same type is inversely proportional to its age.

- Field of use of Aircraft - Classification of aircraft in this respect into two categories:

- Commercial aircraft 


\section{- Private business aircraft.}

In addition to other factors proposed following factors.

- The nature of the previous incidents and the accumulated experience

- The number and nature of the aircraft to be in held, the efficiency of its crew and the efficiency of management.

- The nature of the airports used by aircraft, regular air routes, aircraft use and duration of flight

- The nature of the required insurance cover, the amount of insurance, the amount of loss lost and whether there are conditions for the contract (special benefits or special exceptions).

\section{E - Pricing procedures for Securing and re-securing air fleets}

Aviation insurance needs expensive and expensive possibilities and is often sought first for re-entry before entering into aviation insurance. The London market is the main market for pricing insurance and re-insurance of all air fleets and insurance operations begin through brokers and brokers prepare. The pricing card containing the data is brief about the process to be priced, either from the request for insurance in the case of small operations or from the data prepared and processed by the insured company in conjunction with the airlines and this is done before the beginning of the insurance for a period of not less than one month. A key element in the preparation of the pricing card is to determine the potential maximum commitment represented for aircraft bodies, as the maximum commitment is the largest value and the largest aircraft in the fleet, and for passengers the maximum commitment is the maximum seat (based on international conventions). In the case of international fleets or by agreement between the insurance company and the owner of the aircraft in the case of small operations multiplied by the number of chairs not the largest aircraft and for civil responsibility and the majority of the rest of the coverage is determined the maximum liability is determined by agreement between the airline and the insurance company (Rogers, 2006). The Ma'adi leading insurance with the guidance of the point of view of brokers in this regard and in line with similar fleets or coverage. After receiving instructions for starting pricing, brokers provide the pricing card to leading reinsurers and specialists in the pricing of the process offered to study it and determine the prices, conditions and share they accept from them. Which is humiliating to sign them and in some cases the process is offered more. Finally, the process is submitted to (airlines) to approve the conditions and prices that the pioneers have specified to be approved before submitting them to the rest of the reinsurers to complete the insurance and reinsurance of the fleet (Hassan, 2004).London is a hub for airline insurance, which in turn is classified as a market for brokers, whose role is often limited to securing participation or the voluntary reinsurance of certain companies.

There is a problem experienced by airlines operating in the domestic market, in their dealings with international insurance companies, which have made themselves the adversary and judge in any insurance case. That the modest capital in the establishment of local insurance companies, deprived them of participation in the insurance sector on aircraft, and lost them Billions of the income of this sector, that airlines operating in the domestic market secure their aircraft with international insurance companies. However, through national insurance companies, get a small share at best of the value of annuities, while the large percentages go to foreign companies, which monopolize this sector. This made them the opponent and judge in the event of a flight disaster, requiring insurance compensation.

It is necessary to work on the training of human competencies in the insurance sector to work in this field, and the lack of local insurance companies in the aviation market sector. Not only because of the poor solvency of local insurance companies, but also the lack of technical expertise working in this field, knowing that Aircraft are insurance products that generate good profits for insurance companies (Al Arabiya, 2014). 


\section{PRACTICAL IMPLICATIONS OF THE FRAMEWORK}

\section{Administrative Efficiency}

Insurance companies cannot dispense with the re-insurance processes in whole, but the insurance company can increase its retention rates, over time if there is sufficient technical expertise in addition to increasing the company's capital.

Table 1. Shows the retention rates of the National Insurance Company for the aviation insurance portfolio amounted to thousands of dinars.

\begin{tabular}{|l|c|c|c|c|}
\hline Year & $\begin{array}{c}\text { Total } \\
\text { insurance/aviat } \\
\text { ion premiums }\end{array}$ & $\begin{array}{c}\text { Total marine reinsurance/JD } \\
\text { reinsurance }\end{array}$ & $\begin{array}{c}\text { Net marine } \\
\text { insurance/jd }\end{array}$ & $\begin{array}{c}\text { Retention } \\
\text { rate\% }\end{array}$ \\
\hline 2011 & $13,907,819$ & $7,337,408$ & $6,570,411$ & 47 \\
\hline 2012 & $15,443,474$ & $14,270,092$ & $1,173,382$ & 8 \\
\hline 2013 & $12,642,345$ & $13,126,070$ & $(483,725)$ & $(4)$ \\
\hline 2014 & $17,907,450$ & $10,328,469$ & $7,578,981$ & 42 \\
\hline 2015 & $14,813,853$ & $16,709,398$ & $(1,895,545)$ & $(13)$ \\
\hline 2016 & $14,759,911$ & $12,311,368$ & $2,448,544$ & 17 \\
\hline
\end{tabular}

Source of researcher's numbers are based on the reports and financial statements of the National Insurance Company for the period above (Retention rate): That part of the risk held by insurance companies without reference to reinsurance agreements. Please refer to Figure No. 1 for further details.

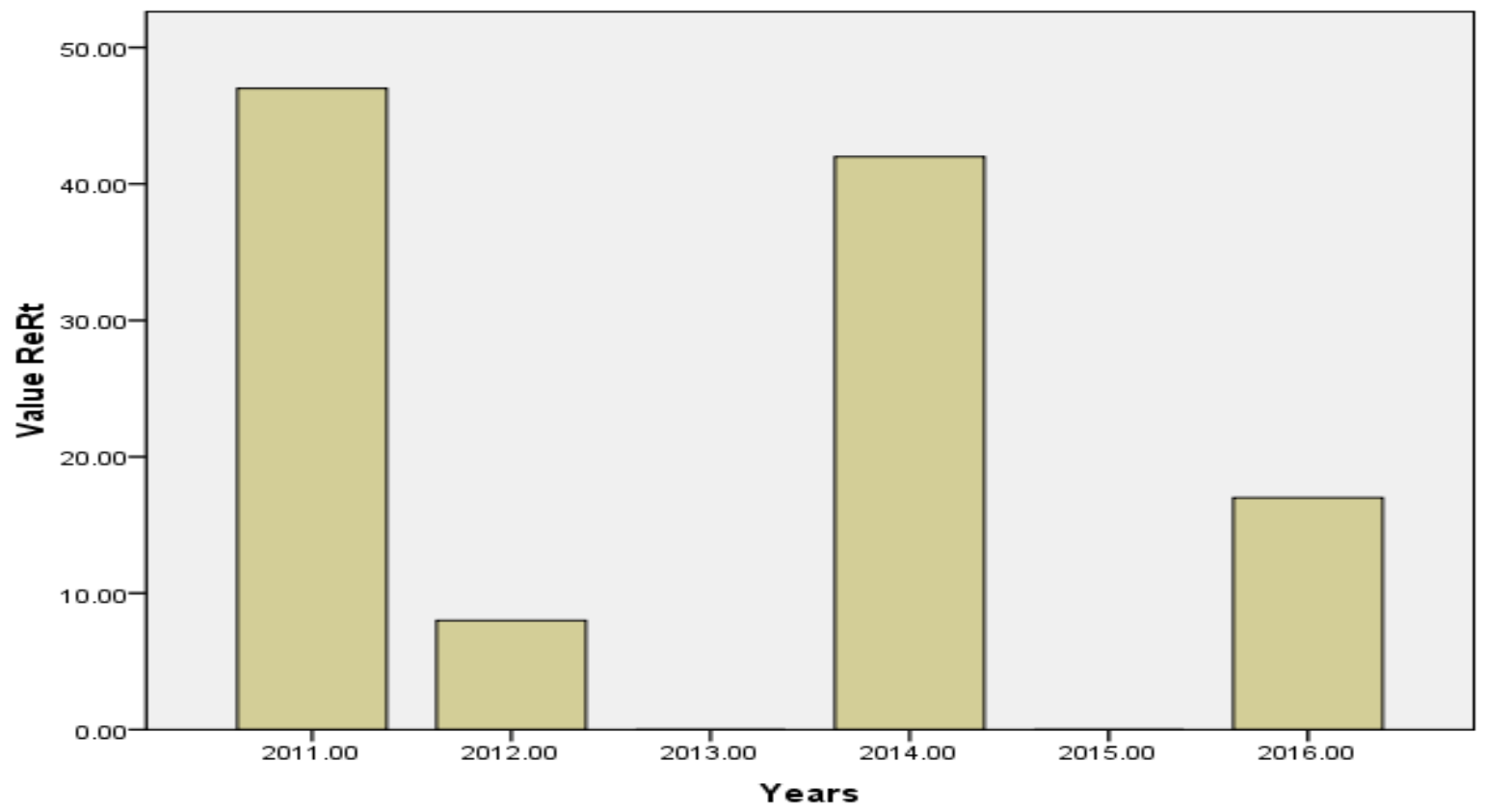

From the table and chart above the researchers have observed that the retention between 2010 and 2016 fluctuates between less than $0 \%$ and $47 \%$ of the total premiums for aviation insurance. While the average retention rate for the years of study is $15 \%$, which means that the national insurance company assigns $85 \%$ of the total insurance premiums to the insurance set. This is due to the poor financial capacity of insurance 
companies, their lack of expertise in dealing with the risks of aviation security and the potential for significant reinsurance risks. It should work to strengthen its financial centres and train its cadres to gain experience in the field of aviation security.

\section{The Relationship between the Total Insurance Premiums and the Reinsurance Premiums IssuedI}

Table 2. Total premiums in aviation insurance and reinsurance premiums.

\begin{tabular}{|l|c|c|c|}
\hline Year & $\begin{array}{c}\text { Total airline insurance } \\
\text { premiums/JD }\end{array}$ & $\begin{array}{c}\text { Total airline reinsurance } \\
\text { premiums/JD 1,000 }\end{array}$ & Return rate \% \\
\hline 2011 & $13,907,819$ & $7,337,408$ & 53 \\
\hline 2012 & $15,443,474$ & $14,270,092$ & 92 \\
\hline 2013 & $12,642,345$ & $13,126,070$ & 104 \\
\hline 2014 & $17,907,450$ & $10,328,469$ & 58 \\
\hline 2015 & $14,813,853$ & $16,709,398$ & 113 \\
\hline 2016 & $14,759,911$ & $12,311,368$ & 83 \\
\hline
\end{tabular}

Source of researcher's numbers are based on the reports and financial statements of the National Insurance Company for the period above is shown is Figure No. 2.

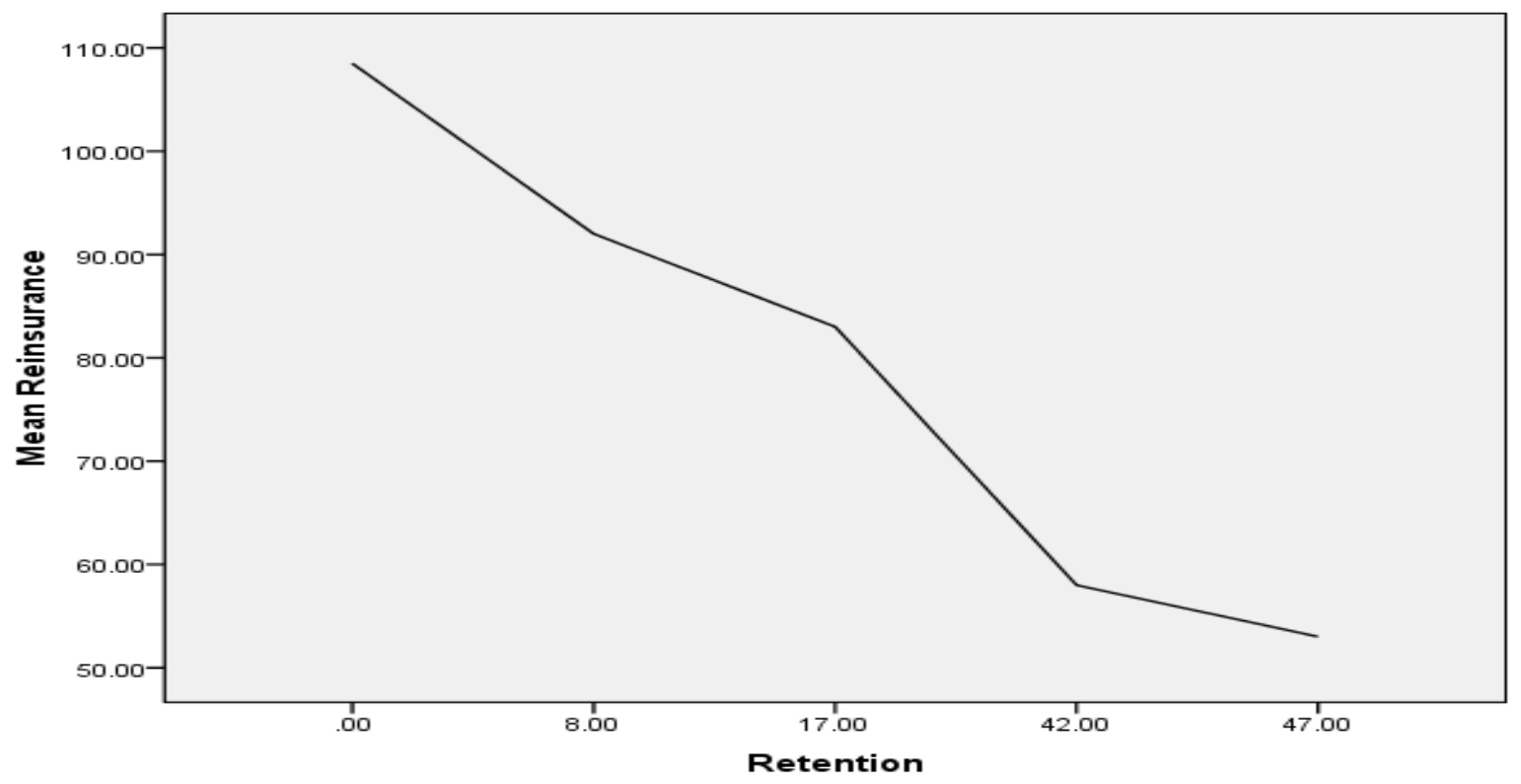

From the table and chart above we have observed that the total premiums subscribed to the National Insurance Company are increasing at different rates and that the rate of re-insurance flight is fluctuating between $53 \%$ to $100 \%$. However, the average rate of return for years of study was $85 \%$ and this indicates an increase in the rate of re-premiums. Thus, the relationship between retention rate and return is reversed.

The Relationship between Administrative Efficiency and the Profitability of the Aviation Insurance Portfolio 
Table 3. Profitability of the Aviation Insurance Portfolio (2011-2012).

\begin{tabular}{|l|l|l|l|}
\hline Year & Profitability/1,000 JD & Net premiums subscribed/JD 1,000 & Profitability rate \% \\
\hline 2011 & $1,557,239$ & $6,570,411$ & 24 \\
\hline 2012 & $3,558,621$ & $1,173,383$ & 303 \\
\hline 2013 & $1,037,031$ & $(483,725)$ & $(214)$ \\
\hline 2014 & $1,249,642$ & $7,578,981$ & 17 \\
\hline 2015 & $5,843,342$ & $(1,895,545)$ & $(308)$ \\
\hline 2016 & $1,327,724$ & $2,448,544$ & 54 \\
\hline
\end{tabular}

Source of researcher's numbers based on the reports and financial statements of the National Insurance Company. For the period above from the table above we see that the rate of profitability during the period studied was generally fluctuating and was increasing during 2012. However, it returned and decreased by (214 , and -308) during 2013 and 2015. The chart shows the relationship between both retention rate and profitability during the period (2011-2016).

\section{ANOVAb}

\begin{tabular}{|ll|l|l|l|l|l|}
\hline Model & & Sum of Squares & df & Mean Square & F & Sig. \\
\hline 1 & Regression & 26320.185 & 1 & 26320.185 & .508 & $.515^{\mathrm{a}}$ \\
& Residual & 207367.148 & 4 & 51841.787 & & \\
& Total & 233687.333 & 5 & & & \\
\hline
\end{tabular}

a. Predictors: (Constant), ReRt

b. Dependent Variable: RePt

Coefficients

\begin{tabular}{|ll|l|l|l|l|l|}
\hline \multirow{2}{*}{ Model } & \multicolumn{2}{|l|}{ Unstandardized Coefficients } & \multicolumn{2}{l|}{$\begin{array}{l}\text { Standardized } \\
\text { Coefficients }\end{array}$} & Sig. \\
\cline { 3 - 5 } & & $\mathrm{B}$ & Std. Error & Beta & & \\
\hline 1 & (Constant) & -86.991 & 131.547 & & -.661 & .545 \\
& ReRt & 3.491 & 4.899 & .336 & .713 & .515 \\
\hline
\end{tabular}

a. Dependent Variable: RePt

The following regression equation represents the relationship between independent variables (administrative efficiency) as a dependent variable (the profitability rate of the aviation insurance portfolio) as described in the table above.

$Y=-86.991-3.491 X$

The model indicates that the $Y$ is $(86,991)$, which means that $(86,991)$ is an independent element in the profitability rate of the aviation insurance portfolio and is influenced by independent variables (retention ratio, reinsurance ratio). The retention ratio affects the profitability of the airline insurance portfolio by 3,491 . This indicates a significant positive correlation between the retention ratio and the profitability of the aviation insurance portfolio, where the single increase in retention ratio increases the profitability ratio by 3,491 . 


\section{CONCLUSION}

After the thorough analysis of the data and interpretation of the analysis, below are some of the conclusions for the present study.

- Aviation insurance finds its roots in London's maritime insurance market. Its origins date back to the 1920s and its history is closely linked to the development of commercial aviation. The financial protection of the aviation insurance industry was critical to the development and support of the aviation industry. Although aviation insurance coverage is offered worldwide, London has always been the main source of protection against aviation-related risks.

- The size of the retention affects the selection of appropriate reinsurance agreements and the amount of reinsurance premiums for the national insurance company.

- The aircraft insurance is a high-premium insurance product that makes good profits for insurance companies.

- The annual reinsurance rates of the Aviation Insurance branch increase and fluctuate up to $100 \%$.

- The study showed a significant reduction in the retention rates of the aviation insurance portfolio of $50 \%$, which is the acceptable range, and this indicates the inefficiency of the management of insurance companies in the use of their assets and the total reliance on reinsurance companies.

- There is an inverse relationship between administrative efficiency and reinsurance premiums for the airline insurance portfolio.

\section{RECOMMENDATIONS}

After the thorough analysis of the data and interpretation of the analysis, below are some of the recommendations for the present study.

- Work to improve the level of administrative efficiency of insurance companies by holding training rotors that will improve employee productivity and reduce expenses by better managing the company's assets. The national insurance company should benefit from the experience of the reinsurer in training its technical staff in surveying and managing risks, which leads to reduced losses.

- To take care of the level of qualification within the company and the use of specialized experts in order to achieve more accurate estimates of the risks assigned and the risks retained.

- Initiating and encouraging policy initiatives with local insurance companies related to the most important hazards such as air transport hazards and their application may help to increase the capacity at home and reduce the use of reinsurance.

- We believe that Arab companies should be established specialized in reinsurance instead of resorting to foreign reinsurance companies because of the large amount of insured Arab funds such as (aviation insurance) by returning to these foreign companies.

- The size of the national insurance company's solvency and reserves should be reviewed each period to determine the size of the capacity.

\section{REFERENCES}

Abbasi, M., \& Zare, A. (2016). Electronic contracts in Iran law. UCT Journal of Social Sciences and Humanities Research, 4(3), 26-31.

Al-Ghussin Ragheb, Lana Nabil Zaher, (2014). "The impact of liquidity, solvency and administrative efficiency on the profitability of insurance companies, "applied study on the Syrian private insurance 
company,research published in the journal tishrin university for research and scientific studies volume (36) issue (3).

Al-Halbawi, Abdullah Tawfiq, (2009). "Maritime and Air Insurance", Freedom Publishing and Distribution Library.

Amoura Reem, (2011)."The impact of efficiency in managing the functions of insurance companies on the success of this company", research published on slide player.

Arabic Net, (2014)."Saudi Aviation Insurance" Al Arabiya Network Magazine.

Coetzee, J., \& Mammen, K. J. (2017). Science and Engineering Students' Difficulties With Fractions At Entry-Level To University. International Electronic Journal of Mathematics Education, 12(3), 281310.

Dewi, S., \& Ahamat, A. (2019). The role of entrepreneurial orientation in achieving organization performance through business model innovation and asset relational collaboration. Humanities \& Social Sciences Reviews, 6(2), 100-105. https://doi.org/10.18510/hssr.2018.6212

Edman, (2019)."Dangers and Air-Manly Marine Insurance", Aradus Arbitration Center.

Guy Callendar, (2009). Efficiency and management, Routledge Studies in Management, USA.

Hassan Mohammed Fouad Mohamed, (2004). "Aviation Insurance sits between balance and challenges (contemporary vision)", research published in The New Horizons, Issue 3 and 4.

Hussein, Hussein Atallah, (2011). "Aviation Insurance", Egypt Insurance Institute.

Hussein, Letim, (2014). "Legal System of Insurance Contract", memorandum submitted to complete the requirements of a bachelor's degree, faculty of law, University of The Meraya and Warqa, Algeria.

Insurance and Knowledge Magazine,(2012). Surrey, Issue 22.

Insurance Schools, (2014). Inc, Licensing Manual Aviation Insurance.

Lutai, Youssef Hajim, Sinan Kazem Al-Musawi, Hussein Jamil Al-Badiri, Hashim Fawzi Al-Abadi, (2011). "Management of Insurance and Risk", Al Yazouri Scientific Publishing and Distribution House, Jordan, First Edition.

Mahmoud, Abu Bakr Mustafa, (2005). "Administrative Organization in Contemporary Organizations", University House, Alexandria.

Margo, Rod. (2000).Aviation Insurance, 3rd ed. (London: Butterworths, 2000).

Radhia, Mashri, (2017). "Lectures in Insurance Law".

Rogers, (2006). translated by Nasser Moussa, Approach to Competencies at the Algerian School, National School Publications Bureau, Algeria.

Safdari, M , Asadi, Z. (2013). Privatization to serve economic development, UCT Journal of Social Sciences and Humanities Research, Issue 4,pp.16-21.

Sebastian Fernandez-Pena, (October 2006). Aviation insurance: a Montreal '99 perspective, Institute of Air and Space Law McGill University, Montreal.

\section{(9) $\odot \Theta \Theta$}

This work is licensed under a Attribution-NonCommercial-NoDerivatives 4.0 International (CC BY-NC-ND 4.0). 